Research Article

\title{
Experimental Investigation of the Liquefaction Properties and Post-Liquefaction Volumetric Strain of Calcareous Sand in Dredger Fill Site
}

\author{
Shenghua Zhao $\mathbb{D D}^{1,2}$ Yanlin Zhao, ${ }^{1}$ Jiang He, ${ }^{1}$ Zhenzhong Cao, ${ }^{2}$ and Lei Wang ${ }^{2}$ \\ ${ }^{1}$ College of Civil Engineering, Guangxi University, Nanning 530004, China \\ ${ }^{2}$ Guangxi Key Laboratory of Geomechanics and Geotechnical Engineering, Guilin University of Technology, Guilin 541004, China
}

Correspondence should be addressed to Shenghua Zhao; 2009025@glut.edu.cn

Received 11 June 2020; Revised 25 August 2020; Accepted 3 October 2020; Published 19 October 2020

Academic Editor: Fengqiang Gong

Copyright (c) 2020 Shenghua Zhao et al. This is an open access article distributed under the Creative Commons Attribution License, which permits unrestricted use, distribution, and reproduction in any medium, provided the original work is properly cited.

\begin{abstract}
In this study, dynamic triaxial cyclic tests were conducted to examine the liquefaction properties and post-liquefaction volumetric strain of calcareous sand from a dredger fill site in the midst of the islands and reefs of the South China Sea. The test results indicated that there were some differences in micromorphology and composition between the calcareous sand obtained via dredging and natural calcareous sand. Axial cyclic stress attenuation can lead to higher cyclic vibration than actual liquefaction vibration, and the modified method can eliminate the effect of axial cyclic stress attenuation. Saturated calcareous sand liquefies under undrained and cyclic loading conditions, and the liquefaction resistance of the calcareous sand decreases with an increase of the effective confining pressure in the dense state. Calcareous sand obtained via dredging exhibited a higher liquefaction resistance compared with other types of calcareous sand. Furthermore, the proposed pore pressure development modified model better describes the pore pressure growth of the calcareous sand from the filling site. The fitting parameters of this model exhibited a high correlation with the relative density. Moreover, the post-liquefaction volumetric strain of the calcareous sand is larger than that of quartz sand, exhibiting a linear relationship with relative density.
\end{abstract}

\section{Introduction}

Coral soil is formed by the physical, biological, and chemical processes corresponding to the remains of marine organisms, such as corals, shells, and algae; because its carbonate content is more than $50 \%$, it is called calcareous soil $[1,2]$. When calcareous soil is dominated by sand silt and its particle gradation can be classified as sandy soil, it is called calcareous sand. Calcareous soil is distributed in the coastal area between $30^{\circ} \mathrm{N}$ and $30^{\circ} \mathrm{S}$ latitudes and covers approximately $40 \%$ of the ocean surface [3]. Many countries have carried out large-scale land reclamation projects, such as the airport expansion project in the Maldives, the Colombo port project in Sri Lanka, and the island and reef filling project in the South China Sea. Most of the materials used in reclamation are obtained by winch or rake suction via large on-board equipment. The calcareous soil obtained through the winch or rake suction process is mainly coral reef debris and coral wreckage. Several structures have been built in these areas; however, these structures are at risk from seismic action. Seismic damage surveys from the 1993 Guam earthquake [4], 2006 Hawaii earthquake [5, 6], and 2010 Haiti earthquake $[7,8]$ indicated that calcareous soil in dredger fill sites can liquefy and cause critical damage. Therefore, it is of great significance to study the liquefaction characteristics and post-liquefaction volumetric strain of calcareous soil to prevent and reduce the risk of an earthquake disaster at calcareous soil sites.

Considerable international research has been performed on calcareous soils in the 1980s as a result of the North Rankin " $A$ " oil platform engineering problems [9]. For instance, Liu and Wang [10], Coop et al. [11], and Zhu et al. [12] studied the mechanical properties, particle breakage, 
and internal pore characteristics of calcareous sand, and $\mathrm{Ma}$ et al. $[13,14]$ studied the mechanical properties of coral sand particles and the compression properties of coral rocks, respectively. These studies demonstrated that calcareous sand is a special geotechnical material with many pores and an irregular shape, and it can be easily broken in a particlebased manner. The engineering properties of calcareous sand are different from those of general continental cohesionless soil. The consensus of many scholars [15-20] is that the liquefaction resistance of calcareous sand is higher than that of quartz sand, but there are still differences in our understanding of whether calcareous sand is liquefied and the influence of various factors on its liquefaction resistance. Gao and Ye [21] noted that calcareous sand in the South China Sea Island and Reef filling site reached a partial liquefaction state under the condition of unobstructed drainage and no liquefaction occurred under these conditions. Hyodo et al. [22] observed that the confining pressure had only a slight effect on the liquefaction resistance (CRR) of calcareous sand with a relative density of $60 \%$. For calcareous sand with a relative density of $80 \%$, the $C R R$ decreased significantly with an increase in the confining pressure. Salem et al. [23] reported that for the same initial relative density and cyclic stress ratio, the number of liquefaction cycles decreased with an increase in the effective confining pressure. Ma et al. [24] considered that the dynamic strength of coral sand in the South China Sea increased with the increase of relative density and effective confining pressure.

However, scholars are more concerned about the liquefaction resistance of calcareous sand and less about the pore pressure growth and volumetric strain after vibration. Sandova and Pando [25] examined the growth characteristics of the excess pore water pressure of calcareous sand and reported that compared with Ottawa quartz sand, Cabo Rojo calcareous sand exhibited a higher $C R R$ as well as a greater fluctuation in the excess pore water pressure curve. Moreover, calcareous sand samples with a higher specific gravity and more uniform grading exhibited a higher $C R R$. Gao and Ye [21] noted that the normalized cumulative pore pressure to vibration ratio of calcareous sand in the South China Sea islands and reefs conformed with the antisinusoidal pore pressure development model proposed by Seed under the undrained condition. Ma et al. [24] considered that the development mode of the pore water pressure of calcareous sand in the South China Sea was considerably different from that of siliceous sand and proposed a modified Seed model for characterization. In addition, research on the volume deformation of calcareous sand has also been discussed. Shahnazari et al. [26] pointed out that the relative density, effective confining pressure, dynamic stress ratio, pore pressure ratio, and maximum shear strain were related to the postcyclic volumetric strain of calcareous sand, and the maximum shear strain was the most important factor. Rezvani et al. [27] studied how physical properties of soil particles play a key role in the mechanical behavior of deposits and provided an estimation method of volume settlement after sand circulation in Hormuz Island.
The above research indicates that conclusions of various studies on the liquefaction characteristics of calcareous sand are different, which may be related to its physical properties. The shape and appearance of calcareous sand in various regions are different, and the particle gradation of calcareous sand obtained using different methods will be different. Therefore, it is necessary to study more liquefaction characteristics of calcareous soil in different regions and sites. The study of post-liquefaction volumetric strain of calcareous sand has an important reference for further study of the antiliquefaction treatment of calcareous sand, i.e., the effective control of drainage conditions of calcareous sand can effectively reduce its potential for liquefaction. To address this, in this study, undrained cyclic triaxial tests of calcareous sand in dredger fill sites of islands and reefs in the South China Sea were conducted. Moreover, the effects of relative density, effective confining pressure, and cyclic stress ratio on the liquefaction resistance of calcareous sand, the pore pressure growth, and post-liquefaction volumetric strain were investigated.

\section{Test Design}

\subsection{Physical Properties of Calcareous Sand}

2.1.1. Shape Characteristics of Calcareous Sand. The calcareous soil used in our tests came from the dredger fill site of the South China Sea Islands and reefs. It is coral debris obtained by the cutter suction or rake suction of large-scale ship-borne equipment. Figure 1 shows screened samples of calcareous sand. The particle size range of the calcareous soil was $0-100 \mathrm{~mm}$, the thicker calcareous soil comprising coral branches and coral reef blocks, and the finer calcareous soil being coral clastic and coral reef block fragments. The calcareous soil was sieved, and the calcareous sand (with a particle size of less than $2 \mathrm{~mm}$ ) accounted for more than $60 \%$ of the total mass. There was more silt in the calcareous sand with a particle size of less than $2 \mathrm{~mm}$. A particle size of less than $0.075 \mathrm{~mm}$ accounted for $5.88 \%$ of the total calcareous sand, which may indicate the occurrence of considerable particle breakage during the cutter suction and dredger filling processes [28]. From its irregular appearance, the thicker calcareous soil shape comprised mainly columnar fragments, including block and limb shapes. The finer calcareous soil comprised columnar, spherical, and block shapes, and the surface of the particles was rough and holey.

Electron microscope scanning tests were carried out on the calcareous sand from the dredger fill site and the natural calcareous sand. Figure 2 shows the SEM images of the two types of sand. It can be seen from the figure that the fine grains of the calcareous sand in the dredger fill site were irregular in shape (column, block, and angle), with uneven surfaces and undeveloped pores. The natural calcareous sand was mainly spherical in shape but comprised irregular angular and columnar shapes. Compared with the calcareous sand from the dredger fill site, the biggest difference was that the surface was full of holes, the larger holes containing the remains of marine microorganisms. 

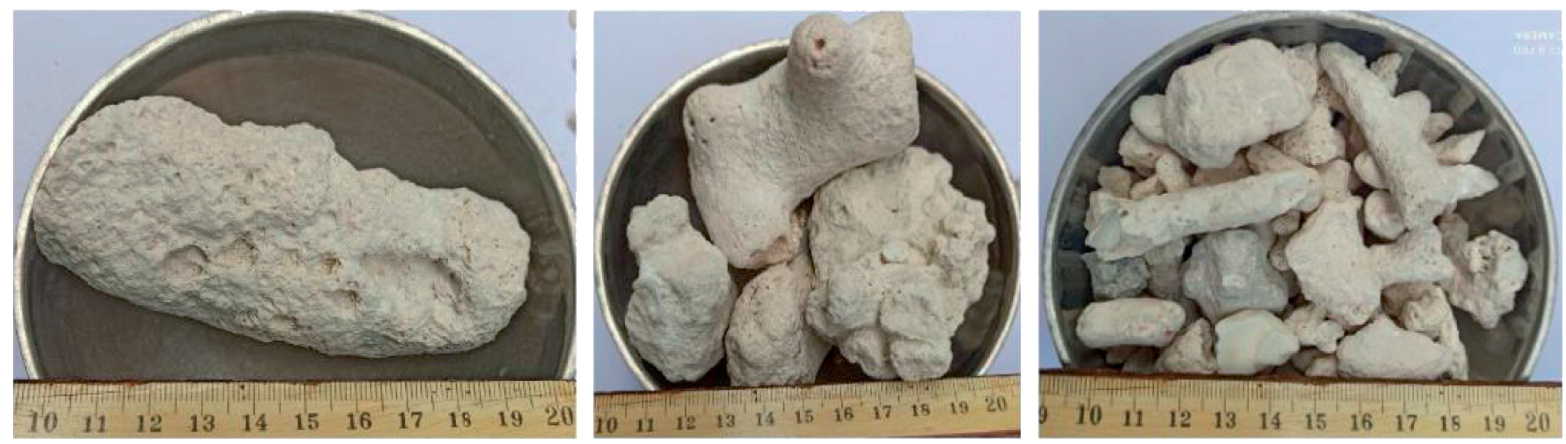

(a)
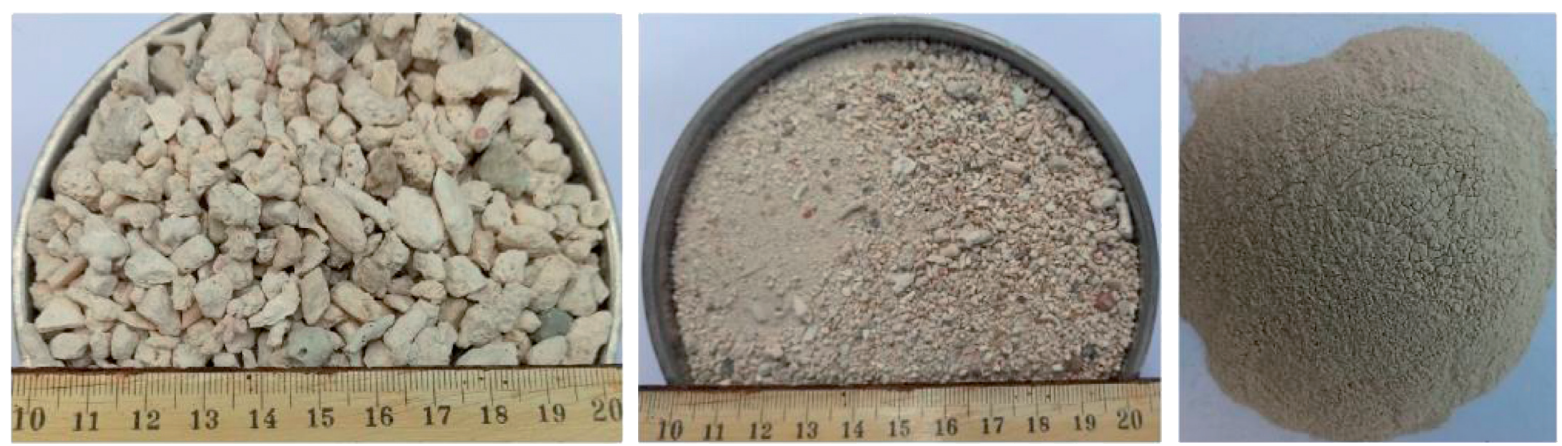

(b)

Figure 1: Calcareous sand samples with different particle sizes (mm).
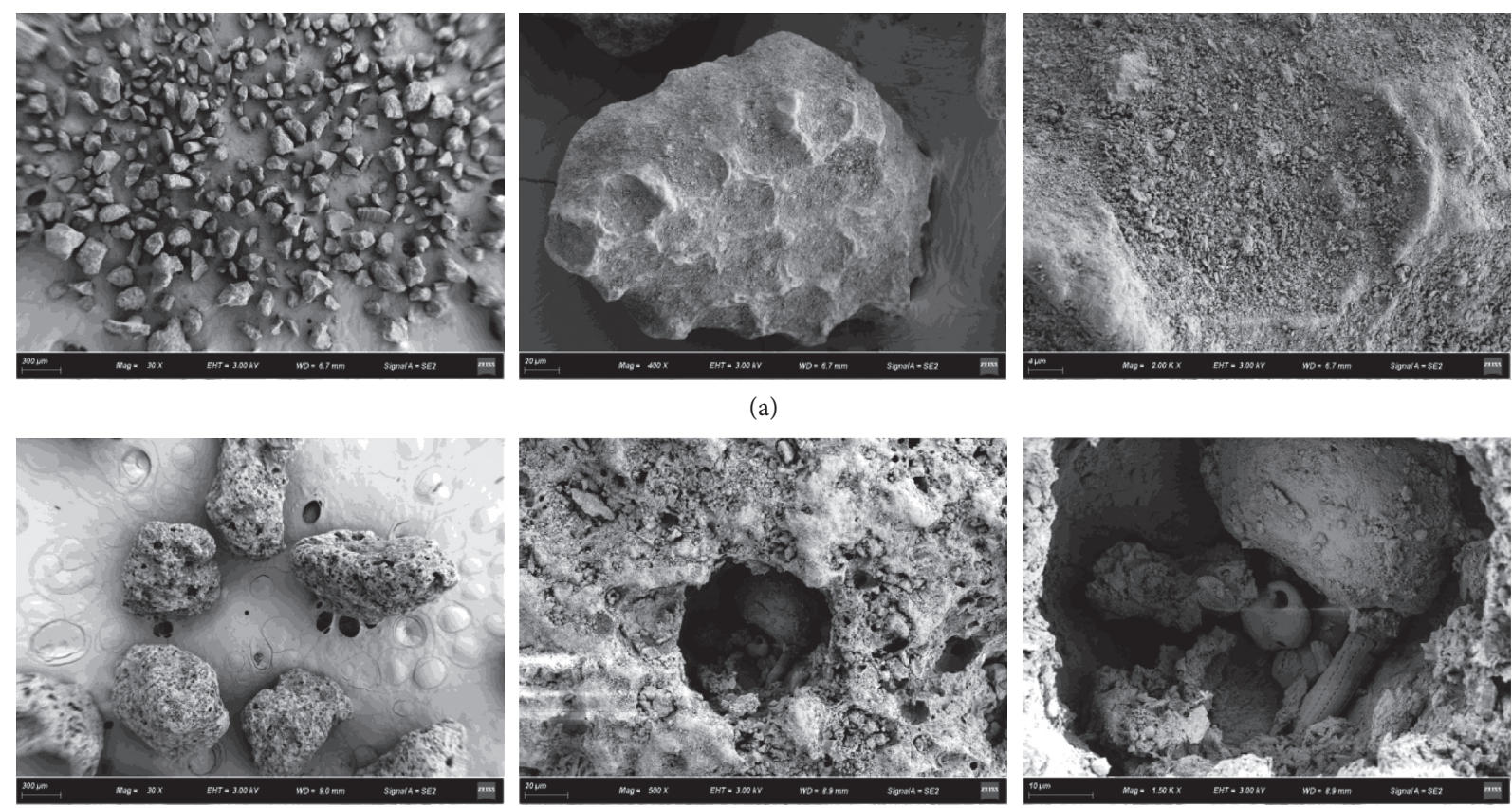

(b)

Figure 2: SEM images of calcareous sands. (a) Calcareous sand from dredger fill site. (b) Natural calcareous sand. 
The above analysis shows that the particle shape and micromorphology of the calcareous sand from the dredger fill site obtained by cutter suction or trailing suction are quite different from those of the natural calcareous sand, which significantly affects the mechanical properties of the calcareous sand.

2.1.2. Physical Properties of Calcareous Sand. The soil samples had a particle size of $0-2 \mathrm{~mm}$, and Fujian standard sand of China was used as the siliceous sand sample. Table 1 lists the physical properties of the calcareous and the Fujian sands, and Figure 3 shows their gradation curves, determined according to the Geotechnical Test Rules SL237-1999 (Nanjing Hydraulic Research Institute) [29]. The $G_{s}$ of the calcareous sand is larger, the curvature coefficient is $1<C_{c}=1.53<3$, and the nonuniformity coefficient is $C_{u}=4.82$. This indicates that the grading curve of calcareous soil is continuous, and the variation range of grain composition is wide, which is close to the index of nonuniform soil. The equivalent carbonate content of the calcareous sand is more than $99 \%$, according to XRF element analysis.

2.2. Sample Preparation and Testing Procedures. The diameter and height of the sand samples were $50 \mathrm{~mm}$ and $100 \mathrm{~mm}$, respectively. When the ratio of height to diameter is 2.0, the phenomenon of stress concentration can be effectively eliminated [30]. Dry packed samples were used. The dried sand was weighed according to the relative density of each sample. Specifically, the sand was poured into the open die in three to five layers and hammered to the design height using a compactor. Scraping was performed between layers to ensure the uniformity of the sample. The finished sample was uniform in size and smooth without obvious rubber film compression, as shown in Figure 4. The rubber film embedding effect of the sample was small and could be neglected [31].

The saturation process of the calcareous sands was as follows: first, after making the sample and connecting the pipeline, air in the $\mathrm{CO}_{2}$ displacement sample, which had a purity of more than $99.9 \%$, was injected from the base intake for 10-20 min. Subsequently, distilled water was added for 30-60 min. Finally, sequential backpressure saturation was performed. When the pore pressure coefficient, $B$, of the sample rose to more than 0.97 , the sand was considered to be saturated.

For isobaric consolidation, the relative density, $D_{r}$, of the calcareous and the Fujian sands was $30-75 \%$ at effective confining pressures, $\sigma_{3 c}$, of $100-400 \mathrm{kPa}$, respectively. After consolidation, undrained cyclic triaxial tests were conducted with applied cyclic stress ratios (CSR) ranging from 0.1 to 0.4 , in increments of 0.05 . Here, CSR $=\sigma_{d} /\left(2 \sigma_{3 c}\right)$, with $\sigma_{d}$ being the axial dynamic stress. The standard dynamic triaxial test system manufactured by UK-based GDS Instruments was employed for the testing. Loading was applied using stress control mode. The input waveform was sinusoidal, and the frequency was $1 \mathrm{~Hz}$. The standard pore pressure ratio $R_{u}=1.0$, and $R_{u}=\Delta u / \sigma_{3 c}$, where $\Delta u$ is the excess pore water pressure [32].
The test procedure was as follows. First, after the sample was saturated, the loading was stopped manually when the sample reached the liquefaction failure standard. Subsequently, the water in the sample was discharged through the volume change controller of the dynamic triaxial apparatus until the excess pore water pressure dropped to zero, and the discharged water was the volume change of the sample after liquefaction [33]. The relative density $D_{r}$ in the chart was the relative density after consolidation.

\section{Results and Discussion}

3.1. Cyclic Triaxial Test Results of Representative Samples. Figure 5 shows the measured time history curve of the volume of discharged water $(V)$, pore water pressure ratio $\left(R_{u}\right)$, axial strain $\left(\varepsilon_{D A}\right)$, and cyclic stress $\left(\sigma_{d}\right)$ of the calcareous and the Fujian sands. It can be observed that with the increase of cyclic vibration times, the cyclic stress $\left(\sigma_{d}\right)$ gradually decreased, as shown by the arrow in the figure. The reason is that with the development of excess pore water pressure, the stiffness of the sample becomes smaller, resulting in softening. The axial strain of the calcareous sand increases gradually, and the axial strain curve begins to warp up until the specimen is destroyed. The axial strain curve of the Fujian sand grows slowly during the initial stage of loading and then rapidly increases after the dynamic stress decays and warps up as a whole due to the instability of the sample. The difference in the axial strain growth modes between the two types of sand also indicates the particularity of the physical properties of the calcareous sand particles. The excess pore water pressure $(\Delta u)$ of the two samples increases continuously with an increase in the cyclic vibration time until $r_{u}=1.0$. After the liquefaction failure of the samples, the drainage volume increases gradually and stays stable after the excess pore water pressure drops to zero, indicating that the drainage process has been completed. The test results of other samples are similar, which shows that the feasibility of the test scheme.

\subsection{Modification of the Number of Cycles to Failure (N).} The dynamic strength of soil reflects the dynamic stress of soil under the condition of failure, which can be expressed as the vibration number required to cause soil failure under certain dynamic stress amplitude. It is expressed by drawing a relationship curve between the cyclic stress ratio (CSR) and the number of cycles $(N)$ during the liquefaction failure of sand samples.

Figure 5 shows that $\sigma_{d}$ remains unchanged in the early stage of loading for both the sands. In the later stage of loading, $\sigma_{d}$ decreases as the specimen stiffness decreases and attenuation occurs before sample liquefaction, as indicated by the arrow in the figure. This phenomenon has been reported in other literature, but there is no relevant treatment. The attenuation of $\sigma_{d}$ leads to an increase in $N$, the liquefaction resistance of the sample is overestimated, and thus $N_{f}$ must be corrected.

Martin and Seed [34] calculated the stress equivalent of seismic waves with irregular stress magnitudes and reported 
TABle 1: Physical properties of various calcareous and siliceous sands.

\begin{tabular}{|c|c|c|c|c|c|}
\hline Type of sand & Calcareous sand & Cataño [19] & Salem et al. [23] & Ma et al. [24] & Fujian sand \\
\hline Specific gravity, $G_{s}$ & 2.87 & 2.86 & 2.79 & 2.80 & 2.65 \\
\hline Diameter corresponding to $50 \%$ finer, $D_{50}(\mathrm{~mm})$ & 0.37 & - & - & 0.31 & 0.662 \\
\hline Diameter corresponding to $10 \%$ finer, $D_{10}(\mathrm{~mm})$ & 0.092 & 0.2 & 0.15 & - & 0.101 \\
\hline Coefficient of uniformity, $C_{u}{ }^{a}$ & 4.82 & 1.05 & 2.4 & 4.67 & 7.82 \\
\hline Coefficient of curvature, $C_{c}^{b}$ & 1.53 & - & - & 0.86 & 2.733 \\
\hline Minimum void ratio, $e_{\max }$ & 1.116 & 1.71 & 1.04 & 1.72 & 0.725 \\
\hline Maximum void ratio, $e_{\min }$ & 0.569 & 1.34 & 0.75 & 0.99 & 0.329 \\
\hline
\end{tabular}

${ }^{\mathrm{a}} C_{u}=D_{60} / D_{10} ;{ }^{\mathrm{b}} C_{c}=D_{30}{ }^{2} /\left(D_{60} \times D_{10}\right)$.

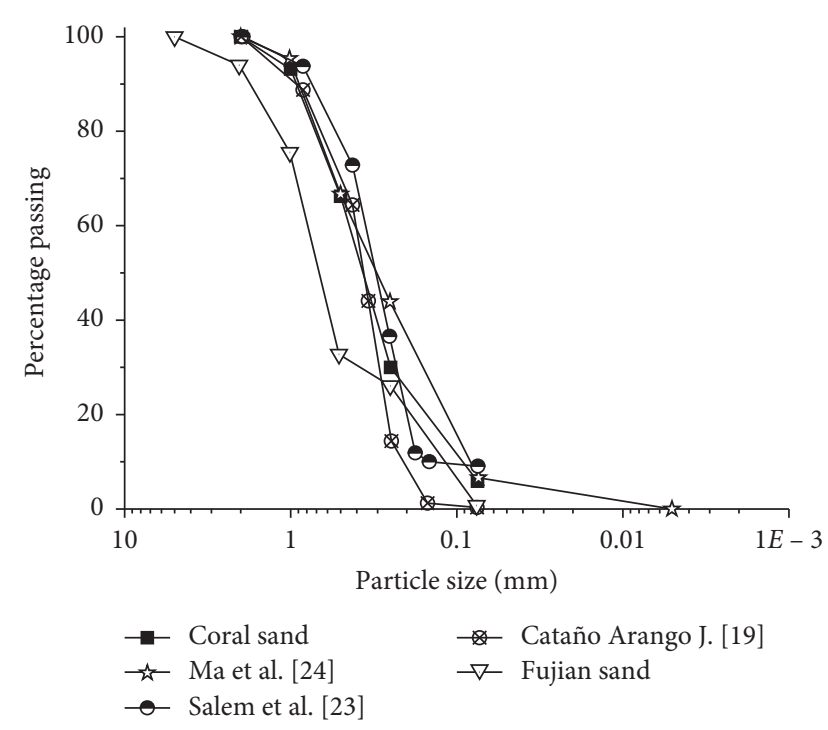

FIGURE 3: Grain-size distribution curves of various calcareous sands and Fujian sand [19, 23, 24].

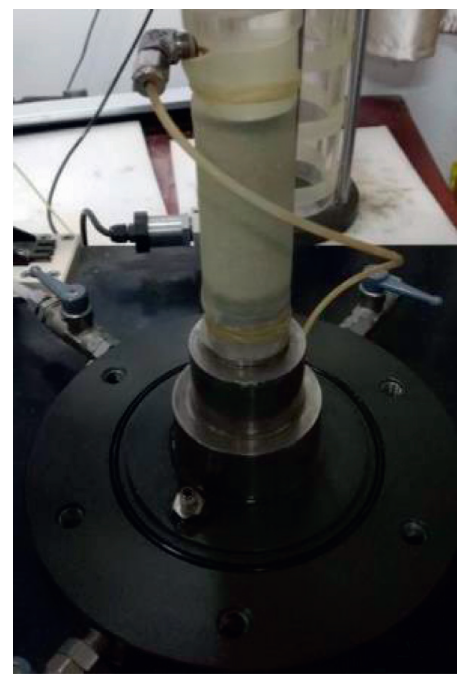

FIgURE 4: Calcareous sand sample.

the corresponding calculation approach. According to this, the number of cycles to failure was modified. The correction method is as follows: firstly, the braking strength curve, CSR $\sim N$, is drawn according to the test results, as shown by the dotted line in Figure 6, and the following formula is obtained:

$$
\mathrm{CSR}=0.561 \times N^{(-0.169)} .
$$

According to equation (1), the CSR and $\mathrm{N}$ of any point on the fitting curve can be obtained.

Next, the dynamic stress time history curve of the specimen is drawn. The cyclic vibration times with the same cyclic stress $\left(\bar{\sigma}_{i}\right)$ are divided into one segment, and the corresponding action times $N_{i}(i=1,2, \ldots, n)$ are obtained, as shown in Figure 7. According to equation (2), the number of actions, $N_{i}$, is converted into an equivalent action number $x_{i}$, as follows:

$$
x_{i}=\frac{N_{i}}{N_{i, L}} \cdot N_{e, L}
$$

where $N_{e, L}$ is the number of cycles determined by the test and $N_{i, L}$ is the cyclic vibration number calculated from equation (1).

Finally, based on equation (3), the equivalent cyclic vibration number $\left(N_{\text {eq }}\right)$ of the sample is obtained, where $N_{\text {eq }}$ is the corrected cyclic vibration number.

$$
N_{\mathrm{eq}}=N_{\mathrm{e}, \mathrm{L}} \cdot \sum_{i} \frac{N_{i}}{N_{i, \mathrm{~L}}} .
$$

The above three steps are repeated to obtain the equivalent cyclic vibration times $(N)$ of all of the samples on the dotted line in Figure 6. The solid line shown in Figure 6 can be obtained, which is the dynamic strength curve corrected by the cyclic vibration number.

It can be seen from equation (3) that $N_{\text {eq }}$ will be equal to $N_{e, L}$ for the case of equal radial stress. According to the above steps for iterative calculation, $N_{\text {eq }}$ will be infinitely close to $N_{e, L}$ for a dynamic stress of variable amplitude. It can be seen from Figure 6 that the fitting effect of the dynamic strength curve after cyclic vibration number $N$ is better. In the case of the same CSR, the corrected cyclic vibration number $N$ is smaller, which indicates that the above correction method of cyclic vibration number $N$ is effective and necessary.

3.3. Cyclic Strength Characteristics of Calcareous Sand. The dynamic strength curve, CSR $\sim N$, of the calcareous sand under different working conditions is drawn after the cyclic vibration times of each sample are corrected using the 


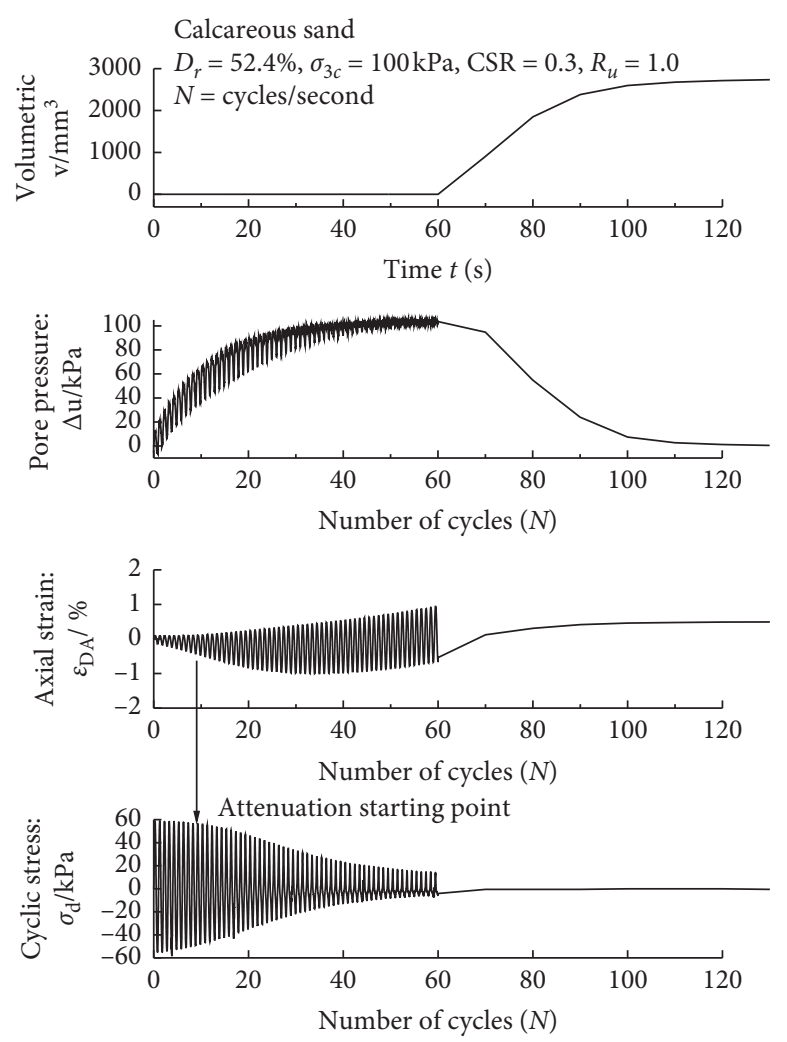

(a)
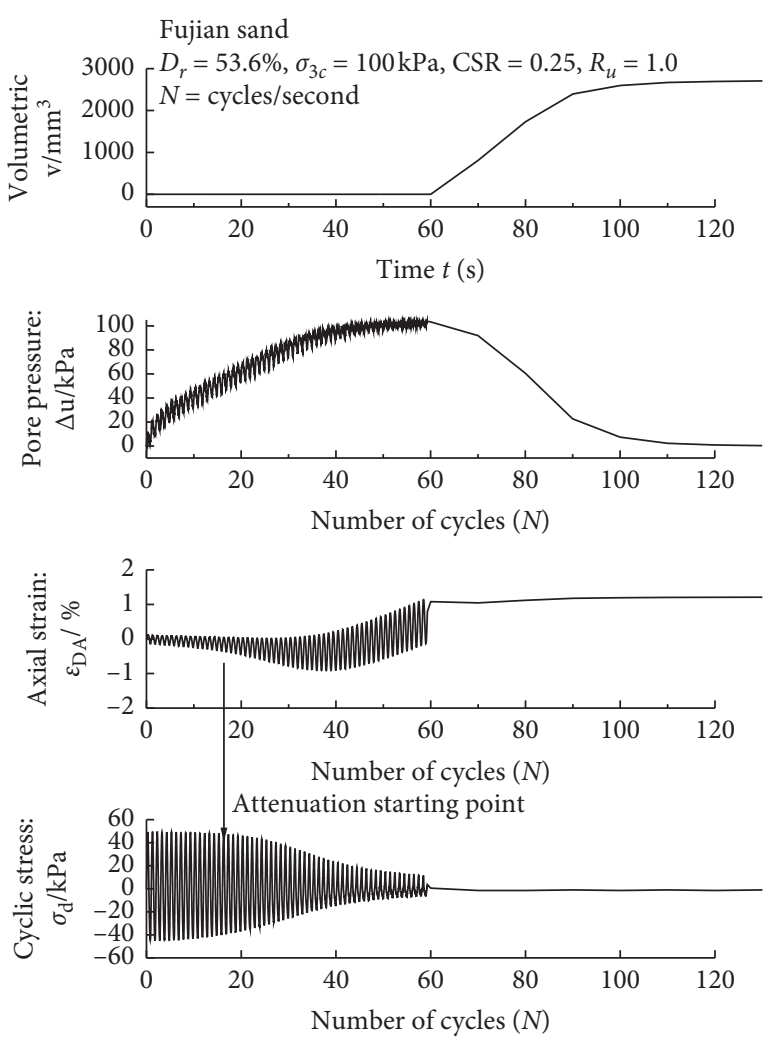

(b)

Figure 5: Cyclic triaxial test results of two types of samples: (a) calcareous sand; (b) Fujian sand.

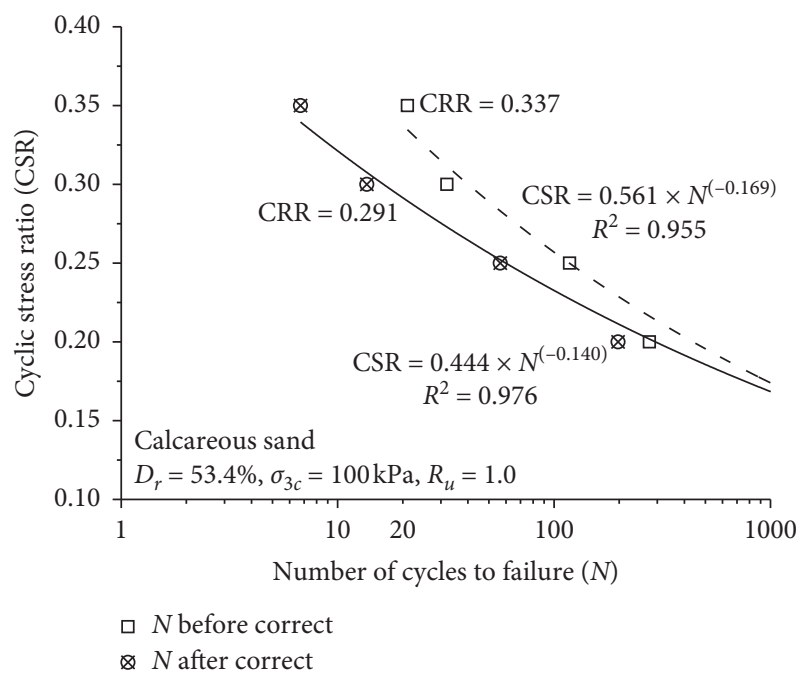

FIgURE 6: Cyclic strength curves of calcareous sand.

above method. It should be noted that the larger $N$ is, the more difficult it is to liquefy the calcareous sand at the same.

3.3.1. Effect of Relative Density on the Cyclic Strength of Calcareous Sand. Figure 8 shows the cyclic strength curve of the calcareous sand under different $\sigma_{3 c}$ values. The cyclic strength curve of the calcareous sands pertains to a negative-

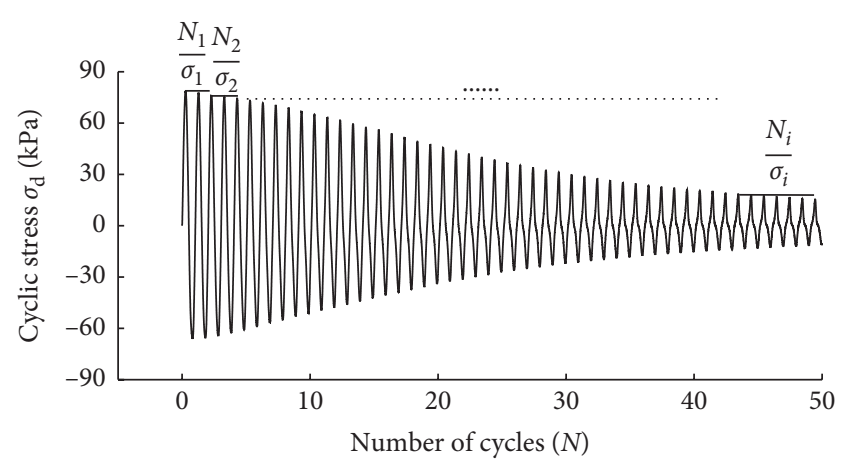

Figure 7: Measured time histories of test results.

ghost exponential function, which is the same as that of siliceous sands. The cyclic strength increases with increasing $D_{r}$; because the porosity of the sand sample decreases, the distance between the sand particles reduces, and the biting force and friction force between the sand particles increases.

3.3.2. Effect of the Effective Confining Pressure on the Cyclic Strength of Calcareous Sand. Figure 9 shows the cyclic strength curve of the calcareous sand for different $D_{r}$ values. It can be observed from the figure that the effect of effective confining pressure on the dynamic strength of the calcareous sand varies with the degree of soil compaction, which is similar to that in reference [22]. In the loose state 


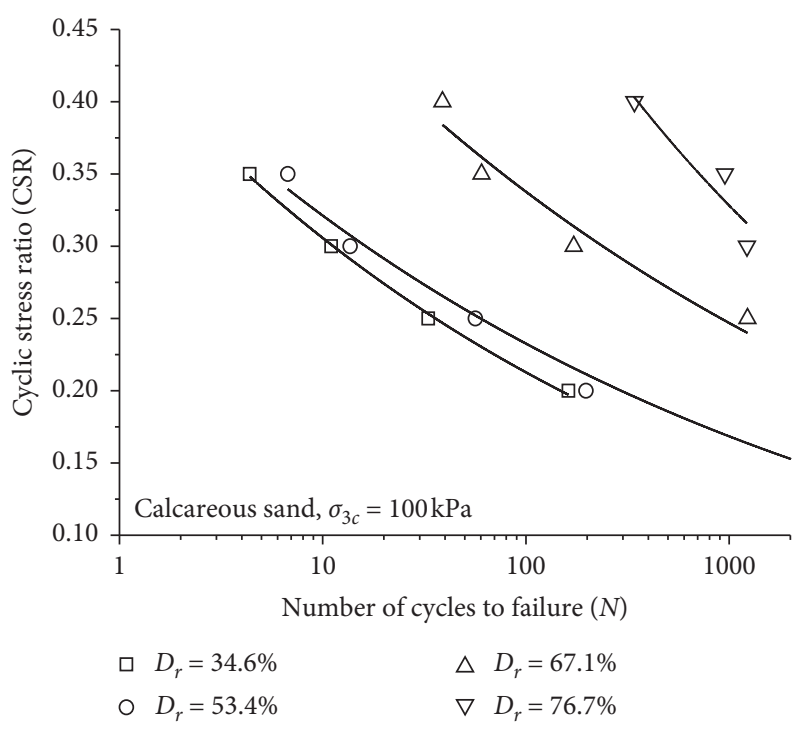

(a)

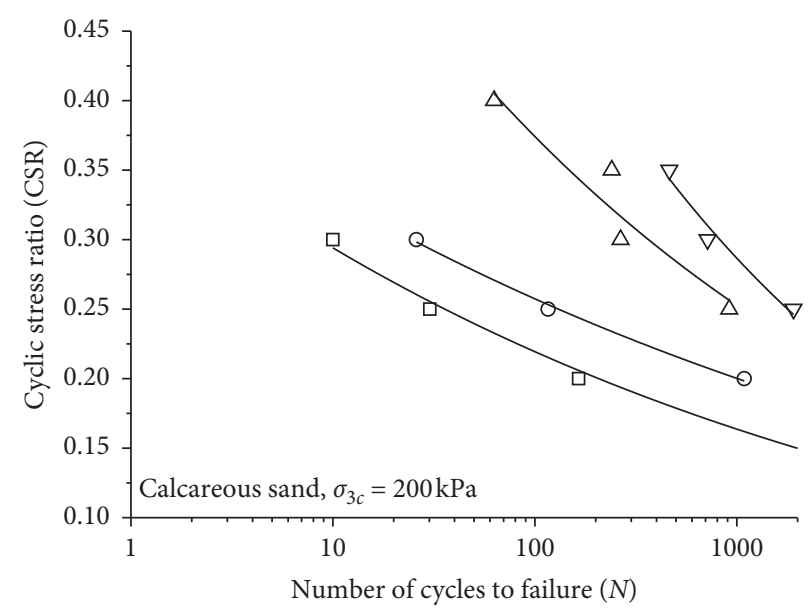
ㅁ $D_{r}=37.3 \%$
$\triangle D_{r}=68.5 \%$
○ $D_{r}=55.2 \%$
$\nabla D_{r}=77.7 \%$

(b)

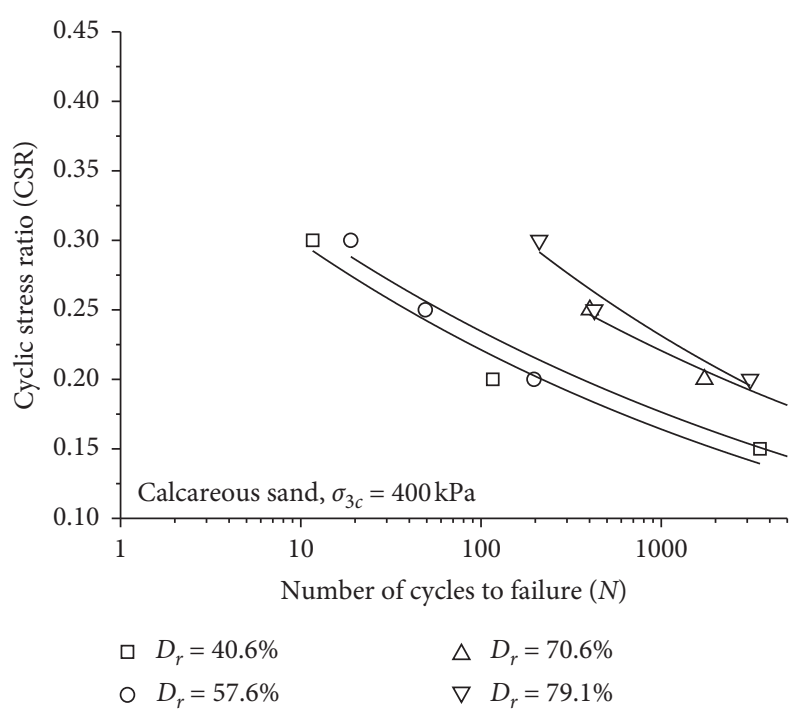

(c)

Figure 8: Effect of $D_{r}$ on the cyclic strength curves of calcareous sand. (a) $\sigma_{3 c}=100 \mathrm{kPa}$. (b) $\sigma_{3 c}=200 \mathrm{kPa}$. (c) $\sigma_{3 c}=400 \mathrm{kPa}$.

$\left(D_{r}<45 \%\right)$, the dynamic strength of the calcareous sand is close. The reason may be that the loose calcareous sand particles do not make close contact, the structural strength is insufficient, and the increase of effective confining pressure has a limited effect on improving the compactness of the calcareous sand particles. When $50 \%<D_{r}<75 \%$ and $\sigma_{3 c}<400 \mathrm{kPa}$, the cyclic strength of the calcareous sand increases with increasing $\sigma_{3 c}$, which is consistent with the results for siliceous sand. This phenomenon occurs because the contact force between the particles increases with increasing $\sigma_{3 c}$. The cyclic strength of the calcareous sand decreases with increasing $\sigma_{3 c}$ when $D_{r}=75 \%$. Weng et al. [35] noted that the crushing degree of the calcareous sand particles increased with the increase of effective confining pressure and the increase of compactness led to the aggravation of particle breakage so that particle breakage reduced the structural strength of sand, thus reducing the dynamic strength of the calcareous sand.

3.3.3. Comparison of the Cyclic Strengths of Calcareous and Siliceous Sands. Figure 10 shows the cyclic strength curves of the calcareous and siliceous sands for different $D_{r}$ values. Both the sands indicate isotropic consolidation. The cyclic strength of the calcareous sand was higher than that of the siliceous sand under the same testing conditions. This is likely due to the calcareous sand involving many edges and irregularly shaped particles, which leads to a higher bite friction between the sand grains than that between the grains of the siliceous sand; this is the same as the literature $[13-20,26]$. This effect is more prominent in a loose state. Martin et al. [36] suggested that under M7.5 earthquakes; the 


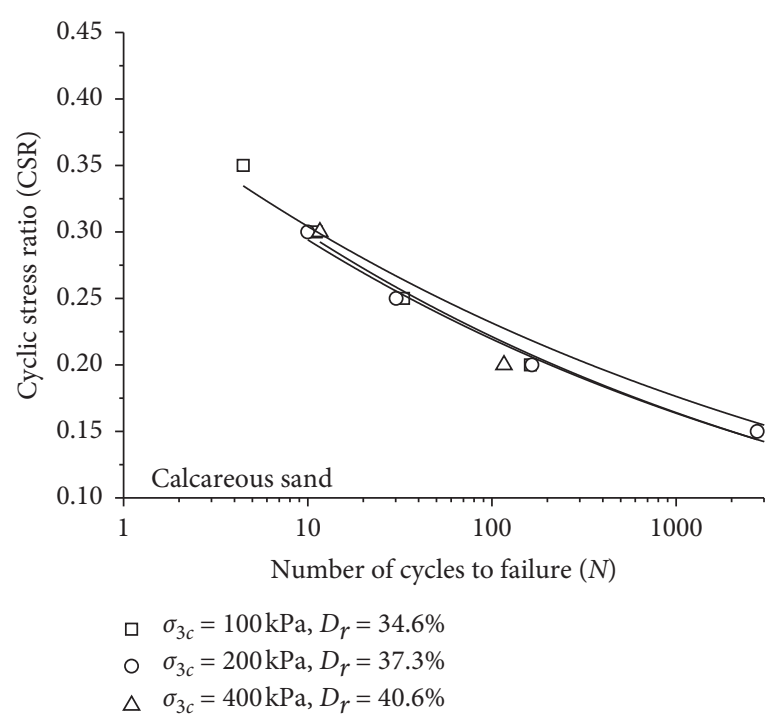

(a)

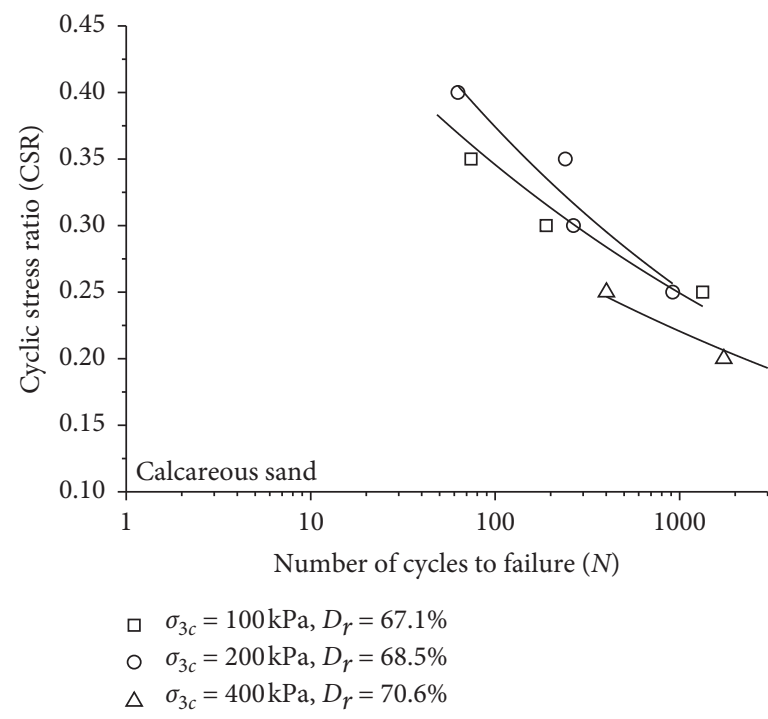

(c)

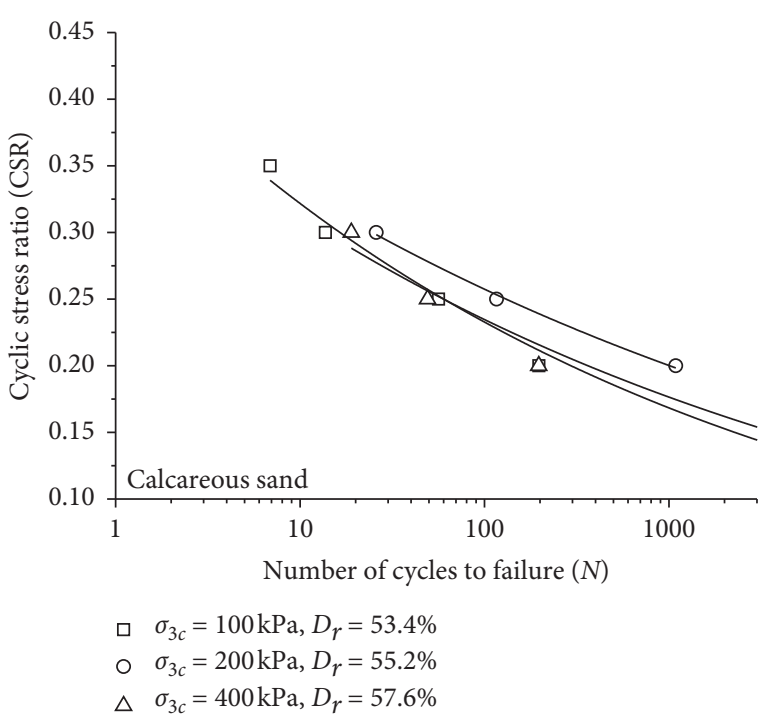

(b)

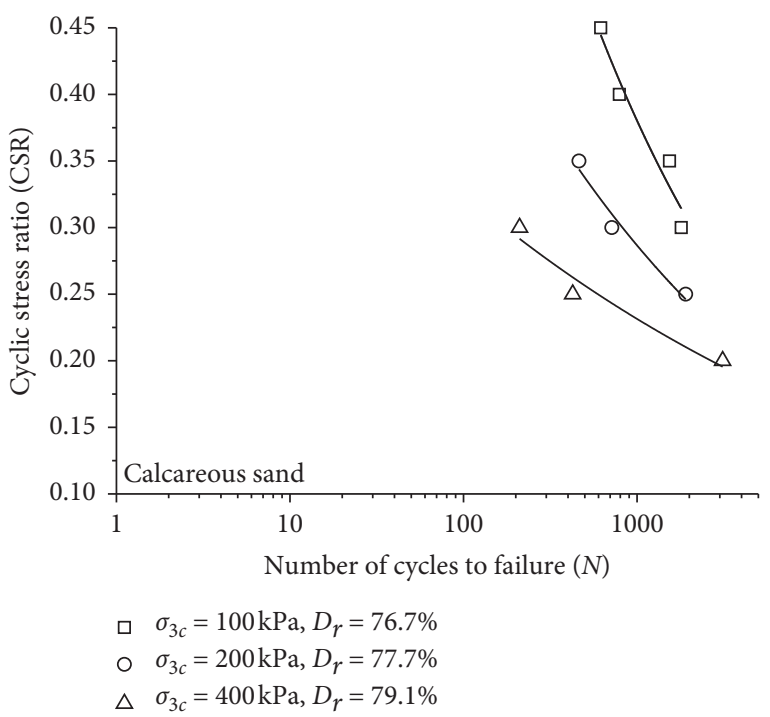

(d)

FIGURE 9: Effect of $\sigma_{3 c}$ on the cyclic strength curves of calcareous sand. (a) $D_{\mathrm{r}}=34.6-40.6 \%$. (b) $D_{\mathrm{r}}=53.4-57.6 \%$. (c) $D_{\mathrm{r}}=67.1-70.6 \%$. (d) $D_{\mathrm{r}}=76.7-79.1 \%$.

CSR corresponding to 20 times the liquefaction under cyclic loading should be used to characterize the CRR of soils.

Table 2 presents the CRR values of the calcareous and the Fujian sands when liquefaction occurs 20 times under cyclic loading for $\sigma_{3 c}=100 \mathrm{kPa}$. It can be observed that under the same working conditions, the dynamic strength of the calcareous sand is close to that of the Fujian sand in the mediumdense state, but it is much higher than that of the Fujian sand in the loose and dense states. A possible reason is that the dynamic strength is determined by the contact force rather than the shape of the particles in the medium-dense state.

3.3.4. Comparison of Cyclic Strengths of Different Types of Calcareous Sands. Figure 11 shows a comparison of the cyclic strength of different types of calcareous sands at $\sigma_{3 c}=100 \mathrm{kPa}$. It can be seen that the cyclic strength of the calcareous sand used in the study is the highest, primarily due to the following reasons:

(1) Grain grading characteristics: Table 1 lists the physical properties of several types of calcareous sands. It can be observed that the calcareous sand employed in this study had a larger $G_{S}$ and better grading.

(2) Influence of particle shape: SEM image analysis shows that the particles of the calcareous sand from the dredger fill site were the fragments and crushed materials of coral reef rocks. Compared with the natural coral sand, the pores were smaller, the surface was rough, and the structural strength of the samples may have been higher. 


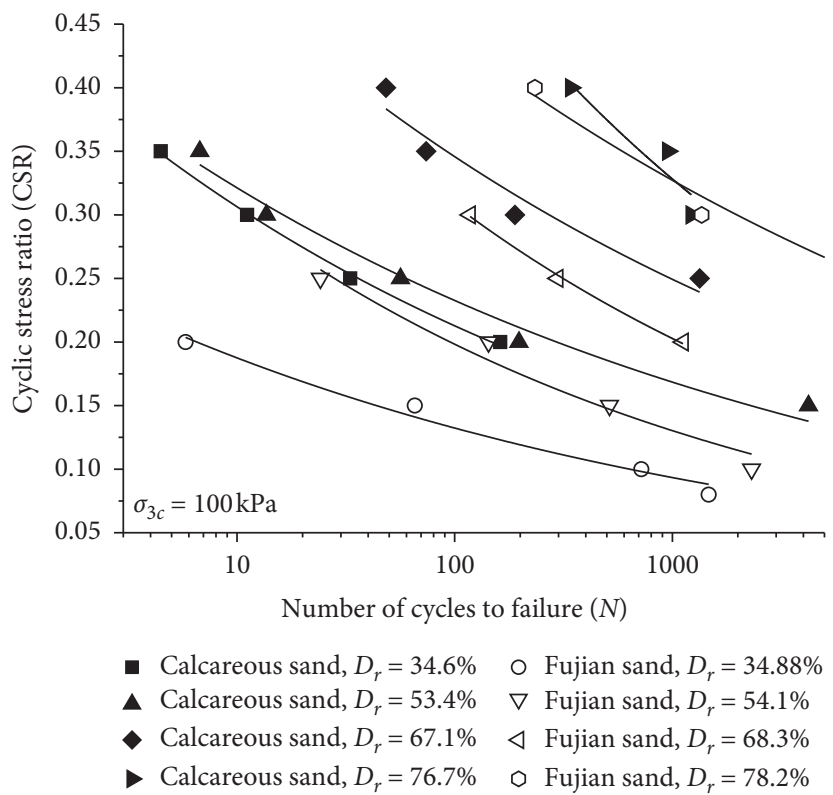

Figure 10: Comparison of cyclic strength of calcareous and Fujian sands.

TABle 2: Comparison of CRR values of calcareous and Fujian sands.

\begin{tabular}{lcccc}
\hline$D_{r}(\%)$ & 34.6 & 53.4 & 67.1 & 76.7 \\
Calcareous sand & 0.280 & 0.291 & 0.420 & 0.693 \\
Fujian sand & 0.169 & 0.268 & 0.412 & 0.538 \\
Percentage difference & 39.68 & 8.02 & 2.06 & 22.37 \\
\hline
\end{tabular}

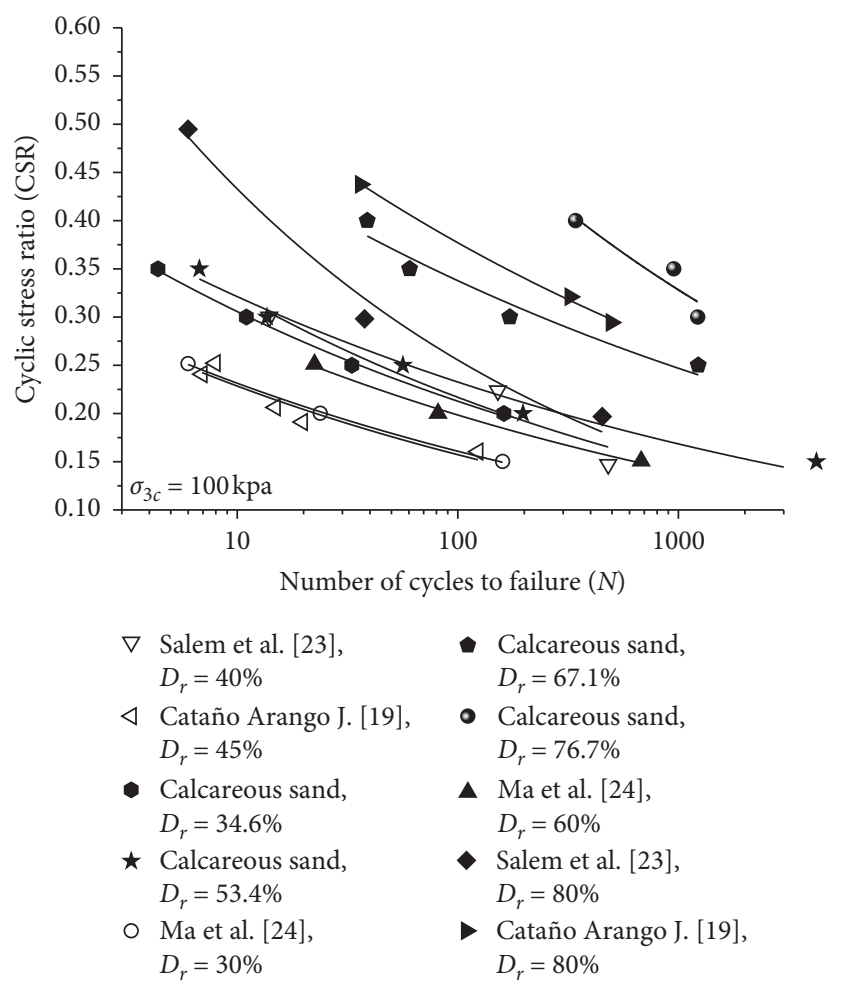

Figure 11: Comparison of the cyclic strength of different types of calcareous sand [19, 23, 24].
(3) Effect of average particle size $D_{50}$ : Martin et al. [37] reported that under the same conditions, the pore pressure growth of undrained soil was proportional to the residual strain of the drained soil; in other words, a larger volume of the undrained soil corresponded to a more rapid pore pressure growth. Moreover, Shen et al. [38] suggested that the coarser calcareous sand particles exhibited a higher compressibility. This means that a larger $D_{50}$ corresponded to a larger change in volume of the calcareous sand. According to Martin's theory, it can be considered that a larger $D_{50}$ corresponds to a higher compressibility of the soil skeleton, and therefore, a more notable soil drainage trend. When no drainage occurs, the pore pressure of the soil increases more rapidly. Therefore, the $D_{50}$ values of the other types of calcareous sand are larger, which correspond to a higher compressibility and more rapid increase in the pore pressure under the undrained conditions, thereby leading to a lower cyclic strength.

3.4. Pore Pressure Growth Characteristics of Calcareous Sands. The development of excess pore water pressure is not only the fundamental reason affecting the deformation and strength of saturated sand but also an important factor affecting the seismic stability of geotechnical engineering. The development of excess pore water pressure is usually described by the relationship between pore water pressure ratio $R_{u}$ and vibration number ratio $N / N_{f}$ of saturated sand, where $N_{f}$ is the cyclic vibration number of the sand liquefaction failure. Pressure on the Pore Pressure Growth. Figures 12(a) and 


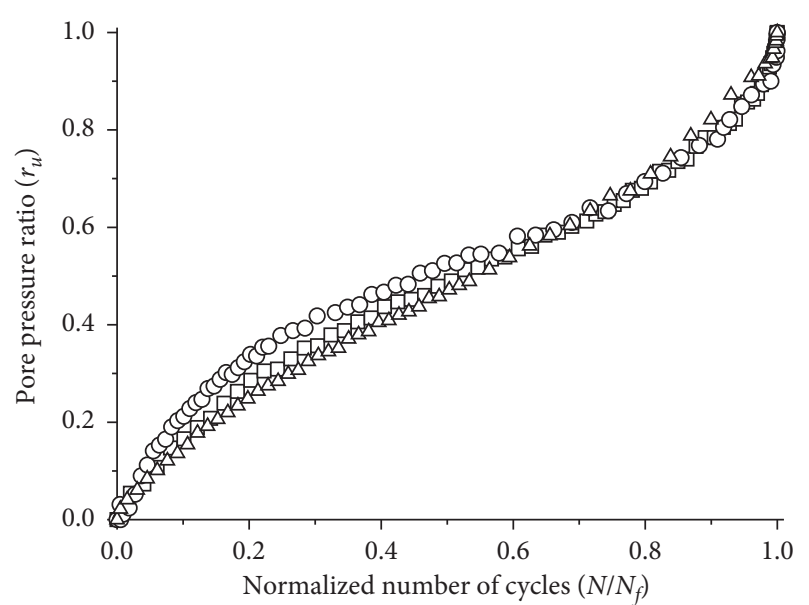

Calcareous sand, $\mathrm{CSR}=0.2$

$\square D_{r}=53.2 \%, \sigma_{3 c}=100 \mathrm{kPa}$

○ $D_{r}=55.2 \%, \sigma_{3 c}=200 \mathrm{kPa}$

$\triangle D_{r}=58.6 \%, \sigma_{3 c}=400 \mathrm{kPa}$

(a)

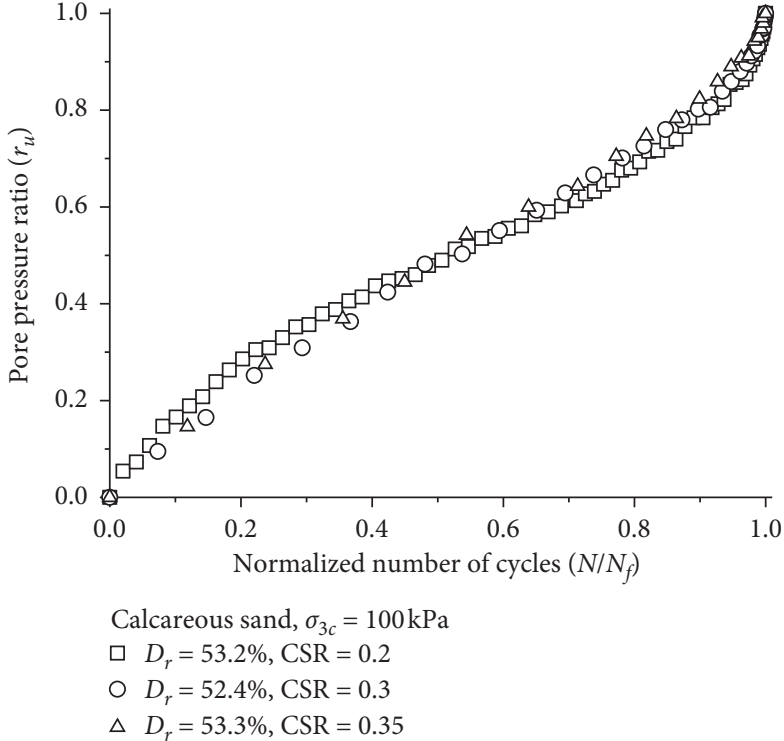

(b)

FIgURE 12: Pore pressure growth curves of typical samples. (a) $\mathrm{CSR}=0.2$ of calcareous sands. (b) $\sigma_{3 c}=100 \mathrm{kPa}$ of calcareous sands.

12(b) show the pore pressure growth curves of the calcareous sand under the following conditions: $D_{r}=53.2-58.6 \%$, CSR $=0.2$, and $D_{r}=53.2-53.3 \%, \sigma_{3 c}=100 \mathrm{kPa}$, respectively. The data points exhibit a high correlation under similar $D_{r}$. This aspect is also true when $D_{r}$ changes.

The formation of excess pore water pressure is caused mainly by the compression of the pores between soil particles under the action of a load, the pore water being too late to discharge, resulting in increasing pore pressure. The irregular calcareous soil has a certain structure. When the relative density is similar to each other, its ability to resist deformation is equivalent. Under different working conditions, the variation of pore compression between soil particles is relatively close, resulting in similar pore pressure development curves.

3.4.2. Effect of the Relative Density on the Pore Pressure Growth of Calcareous Sand. Figure 13 shows the pore pressure growth curves of the calcareous sands for different $D_{r}$ values. It can be observed that the relative density has a great influence on the development of the pore water pressure of the calcareous sand. With the increase of relative density, the pore pressure development curve of the calcareous sand tends to bulge upward. The excess pore water pressure of the loose calcareous sand increases gradually in the process of loading and increases rapidly when it is close to liquefaction failure, similar to quartz sand. In the initial stage of loading, the excess pore water pressure of the calcareous sand develops rapidly and then increases slowly until liquefaction failure. The reason may be that the porosity of the calcareous sand is small under the dense state.

In the initial stage of loading, the pores between the calcareous sand particles are compressed, which leads to the rapid development of pore water pressure. After being

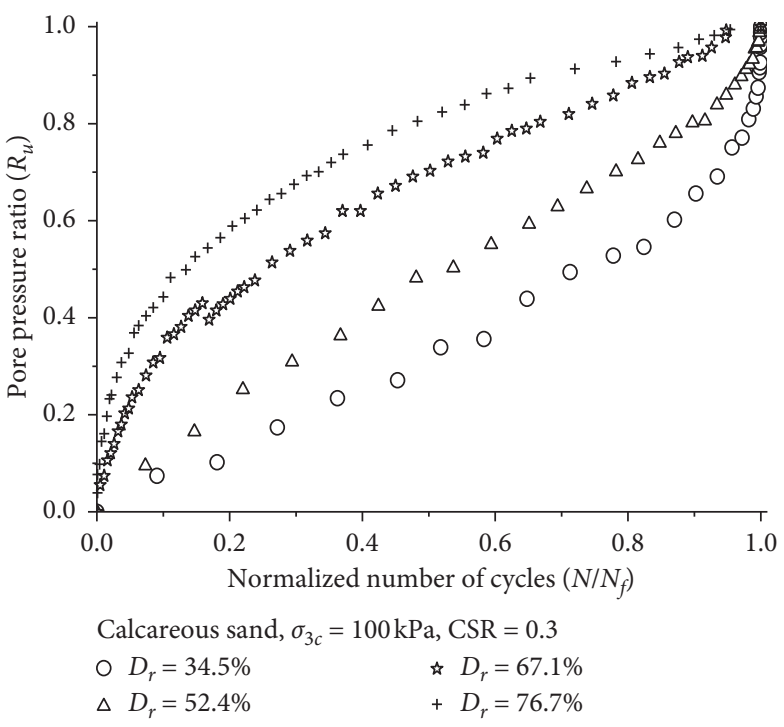

FIGURE 13: Effect of $D_{r}$ on the pore pressure growth curve of calcareous sand.

compacted, the indirect contact force of the calcareous sand particles increases, and the overall structural strength is high. The elastic deformation is the main deformation of the sample, resulting in the slow development of pore pressure.

3.4.3. Comparison of the Pore Pressure Growth Curves of Different Types of Calcareous Sands. Figure 14 shows the pore pressure growth curve of different calcareous sands reported in the literature. It can be observed that the increase in the pore pressure of the calcareous sands exhibits a similar trend. Specifically, in the initial stage of vibration, the pore pressures of the calcareous sands increase rapidly and later 


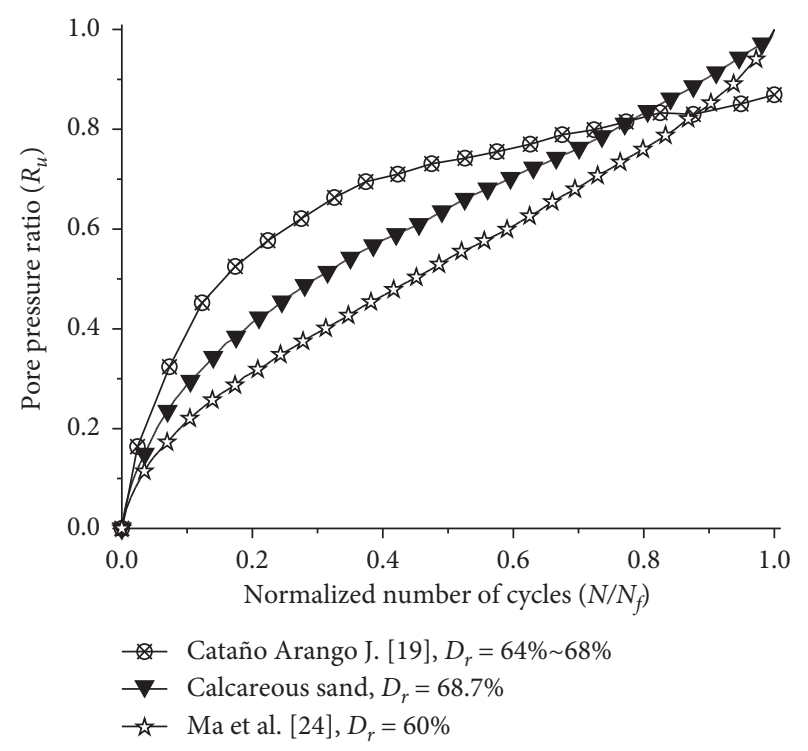

FIGURE 14: Comparison of pore pressure growth curves of different types of calcareous sand $[19,24]$.

decrease. In addition, with increasing $D_{r}$, the pore pressure growth curves of the calcareous sands exhibit an upward convex trend.

The compressibility of the calcareous sand is higher than that of the siliceous sand. For calcareous sand with a larger $D_{r}$ value, the volume change is larger in the initial stage of vibration, and the pore pressure increases more rapidly. After the initial vibration, the $D_{r}$ value is considerably higher, and the volume change caused by the cyclic vibration decreases in the later stage, resulting in a slow increase in the pore pressure.

Overall, $D_{r}$ is a key factor affecting the growth curve of the excess pore water pressure. Figure 14 also shows that the relative density influences the pore pressure growth characteristics of the calcareous sand.

3.4.4. Establishment of Pore Pressure Growth Model for Calcareous Sand. The pore pressure development curves measured under all test conditions in this test are plotted in Figure 15. The pore pressure curves with similar relative density are represented by the same symbol, and the test conditions are shown above. It can be observed that, under different effective confining pressures and cyclic stress ratios, the development rule of the excess pore water pressure is consistent when the relative densities of the samples are similar.

Considering different experimental conditions, several models of the excess pore water pressure growth of saturated sand under cyclic loading in the undrained condition have been developed, among which, the most popular model is the empirical formula based on the test data proposed by Seed et al. [39]:

$$
R_{u}=\frac{1}{2}+\frac{1}{\pi} \sin ^{-1}\left[2\left(\frac{N}{N_{L}}\right)^{1 / \theta}-1\right]
$$

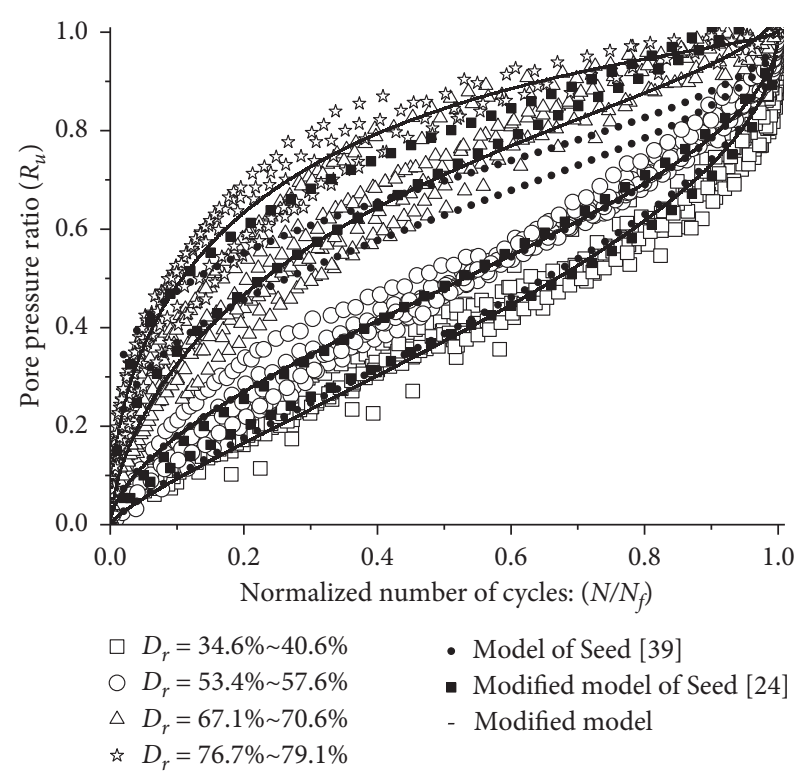

Figure 15: Comparison between the test data and predicted values of excess pore pressure of calcareous sand [24, 39].

where $R_{u}$ is the residual pore pressure ratio after the $N$ th vibration, $N_{L}$ is the number of vibrations when the sample reaches initial liquefaction, and $\theta$ is the test parameter.

At present, there are few studies on pore pressure development models of calcareous sand, especially in the South China Sea. Ma et al. [24] noted that it is not suitable to use the model of Seed directly to describe the pore pressure development of coral sand, so they proposed a modified model of Seed suitable for describing the pore pressure development of coral sands:

$$
R_{u}=a \times \frac{2}{\pi} \arcsin \left(\frac{N}{N_{L}}\right)^{1 / 2 \theta}+b \times \arctan \left(\frac{N}{N_{L}}\right) .
$$

Equations (4) and (5) were used to fit the pore pressure data of the calcareous sand studied in this paper, and the results are shown in Figure 15. It can be seen that the fitting effect of the two models is better when the relative density is small, and the fitting effect of equation (5) is better when the relative density is large. When equation (5) is used to describe the pore water pressure development of the calcareous sand in a dense state, there is some deviation, especially in the later stage of pore pressure development, which cannot reflect the influence of relative density on the development of pore water pressure. Therefore, in this study, a modified model to describe the pore pressure development of the calcareous sand was established based on equation (5):

$$
\begin{aligned}
R_{u}= & (3.92 * \theta-2.6) * \arcsin \left(\frac{N}{N_{L}}\right)^{1 / 2 \theta} \\
& +(3.22-3.9 * \theta) * \arcsin \left(\frac{N}{N_{L}}\right),
\end{aligned}
$$

where $\theta$ is the test parameter, and the fitting curve is shown as a solid line in Figure 15. The fitting parameters of 
TABLe 3: Fitting coefficients of the model.

\begin{tabular}{|c|c|c|c|c|c|}
\hline Model & $D_{r}(\%)$ & $a$ & $b$ & $\theta$ & $R^{2}$ \\
\hline \multirow{4}{*}{ Model of Seed [39] } & 37.5 & - & - & 1.615 & 0.984 \\
\hline & 55.4 & - & - & 1.108 & 0.990 \\
\hline & 68.7 & - & - & 0.522 & 0.916 \\
\hline & 77.8 & - & - & 0.338 & 0.855 \\
\hline \multirow{4}{*}{ Modified model of Seed [24] } & 37.5 & 1.435 & -0.391 & 0.665 & 0.989 \\
\hline & 55.4 & 1.128 & 0.038 & 0.752 & 0.992 \\
\hline & 68.7 & 1.081 & 0.356 & 1.488 & 0.951 \\
\hline & 77.8 & 1.850 & -0.297 & 1.391 & 0.955 \\
\hline \multirow{4}{*}{ Modified model } & 37.5 & - & - & 0.732 & 0.989 \\
\hline & 55.4 & - & - & 0.847 & 0.991 \\
\hline & 68.7 & - & - & 1.003 & 0.964 \\
\hline & 77.8 & - & - & 1.091 & 0.976 \\
\hline
\end{tabular}

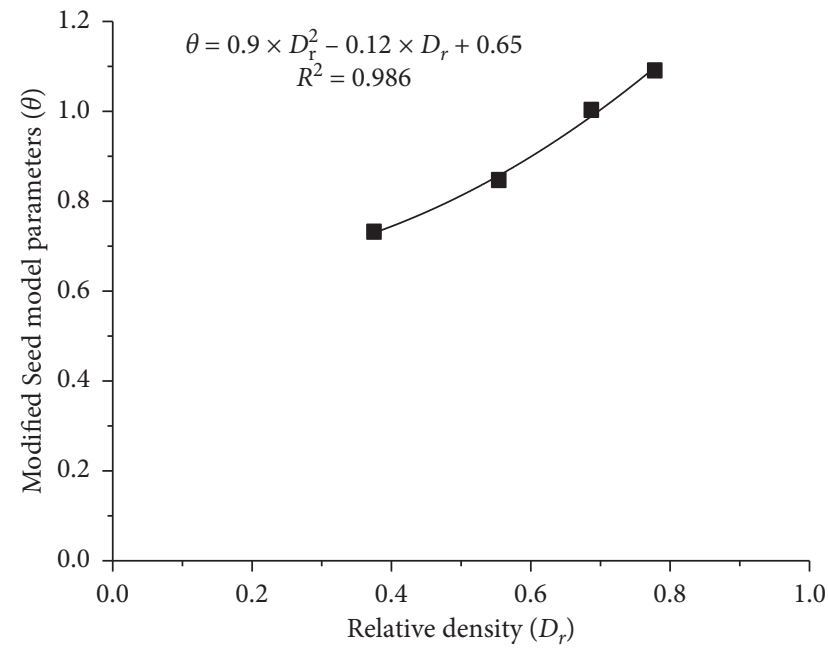

FIgURE 16: Relationship between $D_{r}$ and $\theta$.

equations (4)-(6) are summarized in Table 3, and the average value of the relative density in the table is obtained.

Table 3 shows that the fitting effect of the data with the modified model was satisfactory, with $R^{2}$ being greater than 0.96 . The relationship between the relative density and the modified model parameters was plotted as shown in Figure 16. It can be seen that the consolidated relative density of the calcareous sand was highly correlated with the parameters of the modified model, indicating that the relative density was the main factor affecting the pore pressure growth of the calcareous sand. When the relative density is known, the parameters $\theta$ of the modified model can be obtained by considering Figure 16, making it possible to predict the pore pressure growth curve.

3.5. Volumetric Strain of Calcareous Sand after Liquefaction. When the dynamic load stops, the soil deforms with the dissipation of excess pore water pressure. Scholars have studied the volume deformation characteristics of quartz sand after vibration and achieved many results, but research on the volume deformation characteristics of calcareous sand after liquefaction remains rare. In this test, the effects of relative density, effective confining pressure, and cyclic stress ratio on the volume deformation of saturated calcareous sand after liquefaction are discussed. The volume deformation of the saturated Fujian sand was measured under the same working conditions, for comparison. The volumetric strain after liquefaction is defined as

$$
\varepsilon_{V}=\frac{\Delta V}{V_{0}} \times 100 \%,
$$

where $\Delta V$ is the volume change of sand before and after liquefaction failure and $V_{0}$ is the volume of sand after consolidation.

3.5.1. Effect of Cyclic Stress Ratio on the Post-Liquefaction Volumetric Strain of Calcareous Sand. Figure 17 shows the $\varepsilon_{V} \sim$ CSR curve of the calcareous sand and the Fujian sand after liquefaction. The solid symbol in the figure is the data point of the calcareous sand, and the hollow symbol is the data point of the Fujian sand. The data points with the same relative density and effective confining pressure are plotted on the same curve. It can be seen from the figure that under the same relative density and effective confining pressure, the effect of cyclic stress on the post-liquefaction volumetric strain of the two types of sand is reduced. The reason is that the decrease of porosity is directly proportional to increasing pore pressure. When the porosity of the samples is similar, the change of pore pressure during liquefaction is also similar. Compared to the Fujian sand, the volume of the calcareous sand in the loose state should be higher after liquefaction due to its higher compressibility.

3.5.2. Effect of the Effective Confining Pressure on the PostLiquefaction Volumetric Strain of Calcareous Sand. Figure 18 shows the $\varepsilon_{V} \sim \sigma_{3 c}$ curve of the calcareous sand and the Fujian sand after liquefaction. It can be observed from the figure that when the relative density and cyclic stress ratio are the same, the volume deformation of the calcareous sand after liquefaction increases with increasing effective confining pressure. The volume change of the saturated sand is related to pore pressure. The increase of the effective girth requires more volume deformation in order to achieve the same pore pressure ratio. Therefore, the volume change of sand liquefaction is large. 


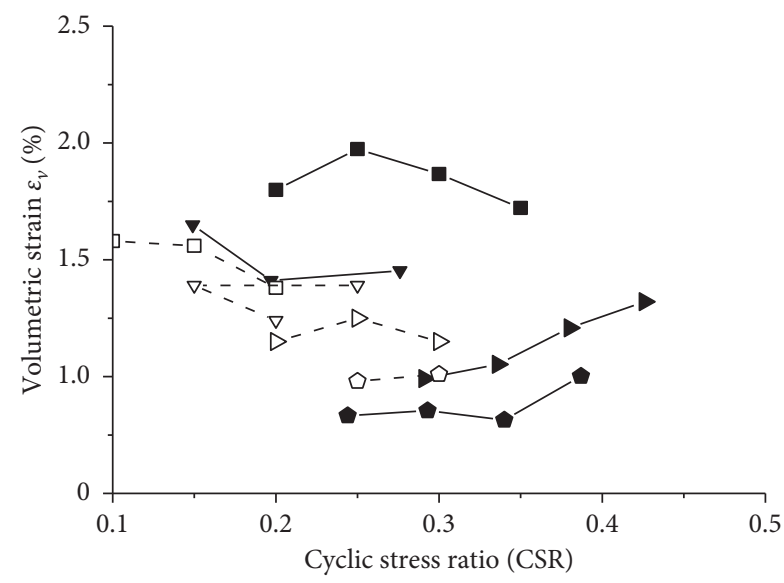

\begin{tabular}{|c|c|}
\hline Calcareous sand, $\sigma_{3 c}=100 \mathrm{kPa}$ & Fujian sand, $\sigma_{3 c}=100 \mathrm{kPa}$ \\
\hline - - $\quad D_{r}=34.6 \%$ & - - $D_{r}=34.9 \%$ \\
\hline$D_{r}=53.4 \%$ & $-\nabla-D_{r}=54.1 \%$ \\
\hline$\rightarrow D_{r}=67.1 \%$ & $-\triangleright D_{r}=68.3 \%$ \\
\hline$D_{r}=76.7 \%$ & $-\checkmark-D_{r}=78.2 \%$ \\
\hline
\end{tabular}

FIgURE 17: $\varepsilon_{V} \sim$ CSR curve of calcareous sand and Fujian sand.

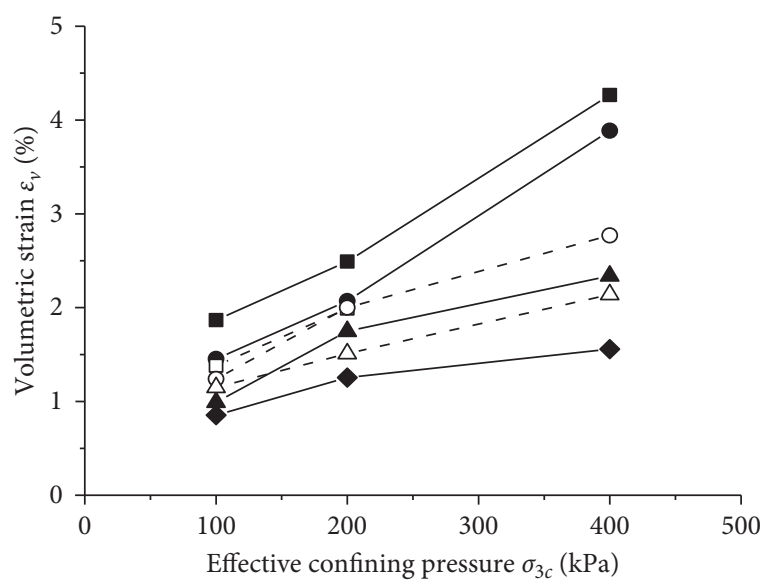

$$
\begin{aligned}
& \text { Calcareous sand, } \mathrm{CSR}=0.3 \quad \text { Fujian sand, } \mathrm{CSR}=0.2 \\
& \text { - - } D_{r}=37.6 \% \quad \text { - }-D_{r}=35.9 \% \\
& \text {-๑ } D r=54.9 \% \text { - O- } D r=55.8 \% \\
& \text { - }-D^{-} D_{r}=68.8 \% \quad-\triangle^{-} D r=69.8 \%
\end{aligned}
$$

Figure 18: $\varepsilon_{V} \sim \sigma_{3 c}$ curve of calcareous sand and Fujian sand.

3.5.3. Effect of Relative Density on the Post-Liquefaction Volumetric Strain of Calcareous Sand. It can be observed from Figure 18 that at the same effective confining pressure and cyclic strain ratio, the post-liquefaction volumetric strain of the calcareous sand increases with decreasing relative density. Lee and Albaisa [33] noted that the average post-liquefaction volumetric strain of quartz sand was related to the relative density. The average value of the postliquefaction volumetric strain of all the calcareous sand and the Fujian sand samples with similar relative density in this test was taken, $\varepsilon_{V} \sim D_{r}$, and a relationship curve was drawn, as shown in Figure 19. The legend in the figure indicates the number of data samples, and the lines in the figure are the

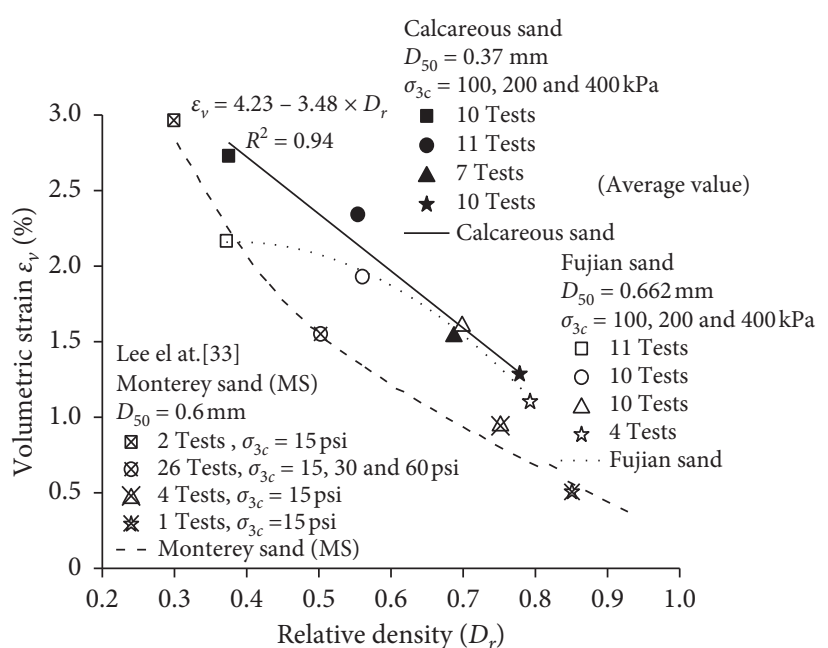

FIgURE 19: $\varepsilon_{V} \sim D_{\mathrm{r}}$ curve of calcareous sand, Fujian sand, and Monterey sand [33].

data fitting lines of the calcareous sand, the Fujian sand, and the Monterey sand [33]. It can be observed from Figure 19 that there is a good correlation between the average value of post-liquefaction volumetric strain of the three types of sand samples and the relative density, but the fitting line of the calcareous sand is linear. The fitting curves of the Monterey sand and the Fujian sand are different in shape, which may be related to the test conditions. The number of samples and the effective confining pressure at the corresponding points of the Monterey sand and the Fujian sand were insufficient. Generally, under the same relative density, the post-liquefaction volumetric strain of the calcareous sand is larger, which may be related to the special particle shape and gradation of the calcareous sand.

\section{Conclusions}

A series of undrained cyclic triaxial tests were conducted on calcareous sand samples obtained from a reef reclamation project site in the South China Sea. The factors influencing the liquefaction resistance, the pore pressure growth, and the post-liquefaction volumetric strain of the saturated calcareous sand were analyzed. The following conclusions were derived:

(i) The particle shape and micromorphology of the calcareous sand from the dredger fill site obtained by cutter suction or trailing suction are quite different from those of natural calcareous sand, which will affect the mechanical properties of the calcareous sand.

(ii) The dynamic stress attenuation leads to cyclic vibration times higher than the actual liquefaction vibration times. A correction method based on the equivalent concept can better eliminate the influence of dynamic stress attenuation.

(iii) Saturated calcareous sand will liquefy under undrained cyclic load. The liquefaction resistance of calcareous sand with high relative density is high, 
but the liquefaction resistance of calcareous sand decreases with increasing effective confining pressure under the dense condition.

(iv) Due to the porous and irregular shape of the calcareous sand, its liquefaction resistance is higher than that of the Fujian sand, and the difference between them is the largest in the loose and dense states. Compared with the calcareous sand studied in other literature, the particle size distribution of the calcareous sand from the dredger fill site was better and had higher anti-liquefaction ability.

(v) The experimental results show that the model of Seed was not suitable for describing the pore pressure development of calcareous sand, and a modified model was proposed, which better described the pore pressure growth characteristics of calcareous sand. The fitting parameters of this model were well-correlated with the relative density.

(vi) The post-liquefaction volumetric strain of the calcareous sand should be larger under conditions of higher effective confining pressure and smaller relative density. The results show that the postliquefaction volumetric strain of the calcareous sand was larger than that of the quartz sand, and the post-liquefaction volumetric strain of the calcareous sand had a linear relationship with relative density.

(vii) The above research has some limitations. It is necessary to further study the influence of different types of calcareous sand shape on liquefaction characteristics and volumetric strain of calcareous sand.

\section{Data Availability}

All data, models, and code generated or used during the study appear in the submitted paper.

\section{Conflicts of Interest}

The authors declare that there are no conflicts of interest regarding the publication of this paper.

\section{Acknowledgments}

We would like to thank Editage (http://www.editage.com) for English language editing. This work was financially supported by the National Natural Science Foundation of China (Nos. 41672296 and 51669005) and the High-Level Innovation Team in the Colleges and Universities and Excellence Scholar Program "Island and Coastal Environment Concrete Structure” in Guangxi of China (No. 201738-2).

\section{References}

[1] P. G. Fookes, "The geology of carbonate soils and rocks and their characterization and description," in Proceedings of the
International Conference on Calcareous Sediments, vol. 2, pp. 787-806, Balkema, Perth, Australia, March 1988.

[2] M. R. Coop and D. W. Airey, "Carbonate sands," in Characterization and Engineering Properties of Natural Soils, T. S. Tan, K. K. Phoon, D. W. Hight, and S. Leroueil, Eds., pp. 1049-1086, Balkema, Rotterdam, Netherlands, 2002.

[3] J. Wang, P. Feng, T. Hao, and Q. Yue, "Axial compressive behavior of seawater coral aggregate concrete-filled FRP tubes," Construction and Building Materials, vol. 147, pp. 272-285, 2017.

[4] L. Mejia and M. Yeung, "Liquefaction of calcareousline soils during the 1993 guam earthquake," Earthquake-Induced Movements and Seismic Remediation of Existing Foundations and Abutments, pp. 33-48, ASCE, Reston, VA, USA, 1995.

[5] E. W. Medley, "Geological engineering reconnaissance of damage caused by the October 15, 2006 Hawaii earthquakes," International Journal of Geoengineering Case Histories, vol. 1, no. 2, pp. 89-135, 2007.

[6] G. Chock, T. Kindred, I. Robertson et al., "Compilation of observations of the October 15, 2006 Kiholo Bay (Mw 6. 7) and Mahukona (Mw 6.0) earthquakes, Hawai'i," Earthquake Engineering Research Institute, vol. 31, 2006.

[7] A. Green, S. M. Olson, B. R. Cox et al., "Geotechnical aspects of failures at Port-au-Prince seaport during the 12 January 2010 Haiti earthquake," Earthquake Spectra, vol. 27, no. 1, pp. S43-S65, 2011.

[8] E. Rathje, J. Bachhuber, B. Cox et al., Geotechnical Engineering Reconnaissance of the 2010 Haiti Earthquake, Geotechnical Extreme Events Reconnaissance, Port-au-Prince, Haiti, 2010.

[9] G. Nyland, "Detailed engineering geological investigation of North Rankin "A" platform site," in Proceedings of International Conference on Calcareous Sediments, pp. 503-512, Perth, Australia, March 1988.

[10] C. Q. Liu and R. Wang, "Preliminary research on physical and mechanical properties of calcareous sand," Rock and Soil Mechanics, vol. 19, no. 3, pp. 32-37, 1998, in Chinese.

[11] M. R. Coop, K. K. Sorensen, T. Bodas Freitas, and G. Georgoutsos, "Particle breakage during shearing of a carbonate sand," Géotechnique, vol. 54, no. 3, pp. 157-163, 2004.

[12] C. Q. Zhu, H. Y. Chen, Q. S. Meng, and R. Wang, "Microscopic characterization of intra-pore structures of calcareous sands," Rock and Soil Mechanics, vol. 33, no. 7, pp. 1831-1836, 2014, in Chinese.

[13] L. J. Ma, Z. Li, M. Y. Wang, H. Z. Wei, and P. X. Fan, "Effects of size and loading rate on the mechanical properties of single calcareous particles," Powder Technology, vol. 342, pp. 961971, 2018.

[14] L. J. Ma, J. W. Wu, M. Y. Wang, D. Lu, and H. Z. Wei, "Dynamic compressive properties of dry and saturated calcareous rocks at high strain rates," Engineering Geology, vol. 272, Article ID 105615, 2020.

[15] B. T. Morioka and P. G. Nicholson, "Evaluation of the liquefaction potential of calcareous sand," in Proceedings of the Annual International Offshore and Polar Engineering Conference, pp. 494-500, Seattle, WA, USA, 2000.

[16] W. S. Kaggwa and H. G. Poulos, "Comparison of the behaviour of dense carbonate sediments and silica sand in cyclic triaxial tests," Research Report No. R611, University of Sydney, Sydney, Australia, 1990.

[17] T. H. Lavielle, Liquefaction Susceptibility of Uncemented Calcareous Sands from Puerto Rico by Cyclic Triaxial Testing, Virginia Tech, Blacksburg, VA, USA, 2008. 
[18] H. G. Brandes, "Simple shear behavior of calcareous and quartz sands," Geotechnical and Geological Engineering, vol. 29, no. 1, pp. 113-126, 2011.

[19] A. J. Cataño, "Stress strain behavior and dynamic properties of cabo rojo calcareous sands," M.S. thesis, University of Puerto Rico, Mayaguez, Puerto Rico, 2006.

[20] H. Shahnazari, Y. Jafarian, M. A. Tutunchian, and R. Rezvani, "Probabilistic assessment of liquefaction occurrence in calcareous fill materials of Kawaihae Harbor, Hawaii," International Journal of Geomechanics, vol. 16, no. 6, 2016.

[21] R. Gao and J. H. Ye, "Experimental investigation on the dynamic characteristics of calcareous sand from the reclaimed calcareous reef islands in the South China Sea," Rock and Soil Mechanics, vol. 40, no. 10, pp. 1-14, 2019, in Chinese.

[22] M. Hyodd, A. F. L. Hyde, and N. Aramaki, "Liquefaction of crushable soils," Géotechnique, vol. 48, no. 4, pp. 527-543, 1998.

[23] M. Salem, H. Elmamlouk, and S. Agaiby, "Static and cyclic behavior of North Coast calcareous sand in Egypt," Soil Dynamics and Earthquake Engineering, vol. 55, pp. 83-91, 2013.

[24] W. J. Ma, G. X. Chen, L. Li, Q. Wu, and J. R. Liu, "Experimental study on liquefaction characteristics of saturated calcareous sand in Nansha Islands under cyclic loading," Chinese Journal of Geotechnical Engineering, vol. 41, no. 5, pp. 981-988, 2019, in Chinese.

[25] E. A. Sandoval and M. A. Pando, "Experimental assessment of the liquefaction resistance of calcareous biogenous sands," Earth Sciences Research Journal, vol. 16, no. 1, pp. 55-63, 2012.

[26] H. Shahnazari, R. Rezvani, and M. A. Tutunchian, "Post-cyclic volumetric strain of calcareous sand using hollow cylindrical torsional shear tests," Soil Dynamics and Earthquake Engineering, vol. 124, no. 9, pp. 162-171, 2019.

[27] R. Rezvani, M. A. Tutunchian, and H. Shahnazari, "Methods for estimating the post-cyclic settlement of Hormuz Island calcareous sand: an experimental study," The European Physical Journal Plus, vol. 135, 273 pages, 2020.

[28] H. Shahnazari and R. Rezvani, "Effective parameters for the particle breakage of calcareous sands: an experimental study," Engineering Geology, vol. 159, no. 9, pp. 98-105, 2013.

[29] Nanjing Hydraulic Research Institute, Specification of Soil Test SL237-1999, China Water Power Press, Beijing, China, 1999, in Chinese.

[30] A. W. Bishop and G. E. Green, "The influence of end restraint on the compression strength of cohesionless soil," Geotechnique, vol. 15, pp. 244-266, 1965.

[31] E. D. Mark and H. B. Seed, Undrained Cyclic Triaxial Testing of Gravels-The Effect of Membrane Compliance, University of California, Berkeley, CA, USA, 1987.

[32] H. B. Seed and K. L. Lee, "Liquefaction of saturated sands during cyclic loading," Journal of the Soil Mechanics and Foundation Division, vol. 92, no. 3, pp. 25-58, 1966.

[33] K. L. Lee and A. Albaisa, "Earthquake induced settlements in saturated sands," Journal of the Geotechnical Engineering Division, vol. 100, no. 4, pp. 387-406, 1974.

[34] P. M. Philippe and H. B. Seed, The Generation and Dissipation of Pore Water Pressures during Soil Liquefaction, University of California, Berkeley, CA, USA, 1987.

[35] Y. L. Weng, J. Yin, W. J. Chen, K. F. Yu, and X. Z. Wang, "Influencing factors for particle breakage of the calcareous sand under triaxial tests," Soil Engineering and Foundation, vol. 33, no. 3, pp. 295-298, 2019.
[36] G. R. Martin, W. D. L. Finn, and H. B. Seed, "Fundamentals of liquefaction under cyclic loading," Journal of the Geotechnical Engineering, vol. 101, no. 5, pp. 423-438, 1975.

[37] G. R. Martin, W. D. L. Finn, and H. B. Seed, "Effects of system compliance on liquefaction tests," Journal of The Geotechnical Engineering Division, vol. 104, no. 4, pp. 463-479, 1978.

[38] Y. Shen, X. Shen, Y. M. Yu et al., "Macro-micro study on compressive deformation properties of calcareous sand with different particle fraction content," Rock and Soil Mechanics, vol. 40, no. 10, pp. 3733-3740, 2019, in Chinese.

[39] H. B. Seed, J. Lysmer, and P. P. Martin, "Pore-water pressure changes during soil liquefaction," Journal of the Geotechnical Engineering, vol. 102, no. 4, pp. 323-346, 1976. 